\title{
- Plastia em duplo "M" ou "V" para mastectomia
}

- Double "M" or "V" plasty for mastectomy

* Maria Cristina de Oliveira Cardoso Coelho ${ }^{1}$ - CRMV-PE n ${ }^{0} 1381$

Luís Teles Coutinho ${ }^{2}$ - CRMV-PE n ${ }^{0} 2553$

Marília Lorenzoni Aceto ${ }^{2}$ - CRMV-PE n 2534

Vanda Lúcia Monteiro ${ }^{3}$

Paula Fernanda Barbosa de Araújo ${ }^{3}$

Karina Medeiros Britto ${ }^{3}$

${ }^{1}$ Professora Adjunta da Disciplina de Clínica Cirúrgica - UFRPE.

${ }^{2}$ Médico (a) Veterinário (a) autônomo (a).

3 Acadêmicas de Medicina Veterinária - UFRPE.
*Departamento de Medicina Veterinária Universidade Federal Rural de Pernambuco

Rua Dom Manoel de Medeiros s/n Dois Irmãos. Recife/ PE Fone: 4414577 r. $404 / 476$ e-mail: cgzen@truenet.com.br

\section{RESUMO}

A distribuição dos cinco pares de glândulas mamárias dos cães é mediana e as mesmas são paralelas, no sentido da região axilar à parainguinal. A neoplasia mamária é a patologia mais comum destas glândulas e é referida como a principal causa de indicação para mastectomia. A plastia em duplo "M" ou "V" é descrita como alternativa para a obtenção de resultados cicatriciais e estéticos melhores.

Palavras-chave: plastia, neoplasia, mastectomia.

\section{Introdução}

egundo O' KEEFE (1997), tumor é um grande agregado de células descendentes de uma única célula ou clone "fundador", originalmente uma célula de funcionamento normal que, de algum modo, sofreu alteração, pela qual começou a se dividir e proliferar automaticamente, gerando bilhões de outras células similarmente alteradas e constituintes da massa tumoral.

As glândulas mamárias estão distribuídas, nos cães, em duas fileiras paramedianas paralelas desde a região axilar até à inguinal (ELLENPORT, 1986) podendo ser classificadas por nomes (torácicas, cranial e caudal; abdominais, cranial e caudal, e inguinais) ou por números (um a cinco, craniais e caudais) (McCAW, 1996).
O fornecimento sangüíneo das glândulas mamárias torácicas craniais e caudais é realizado pelos ramos da artéria torácica interna, das artérias intercostais e pela artéria torácica lateral. As glândulas abdominais craniais são supridas pelas artérias epigástricas superficiais craniais. Já as glândulas abdominais caudais e as glândulas inguinais são irrigadas pela artéria epigástrica superficial caudal e por ramos da artéria pudenda externa (ELLENPORT, 1986; HARVEY, 1996).

A neoplasia é a doença mais comum das glândulas mamárias e a principal causa de indicação para mastectomia nas cadelas e nas gatas (Figura 1). Essa enfermidade afeta animais de meia-idade e animais idosos, com maior incidência entre dez a onze anos (McCAW, 1996; O’KEEFE, 1997; JOHNSTON, 1998). 
COELHO, M. C. O C.; COUTINHO, L. T.; ACETO, M. L.; MONTEIRO, V. L.; ARAÚJO, P. F. B.; BRITTO, K. M. Plastia em duplo "M" ou "V" para mastectomia / Double " $M$ " or "V" plasty for mastectomy. / Rev. educ. contin. CRMV-SP / Continuous Education Journal CRMV-SP, São Paulo, volume 3, fascículo 3, p. $033-036,2000$.

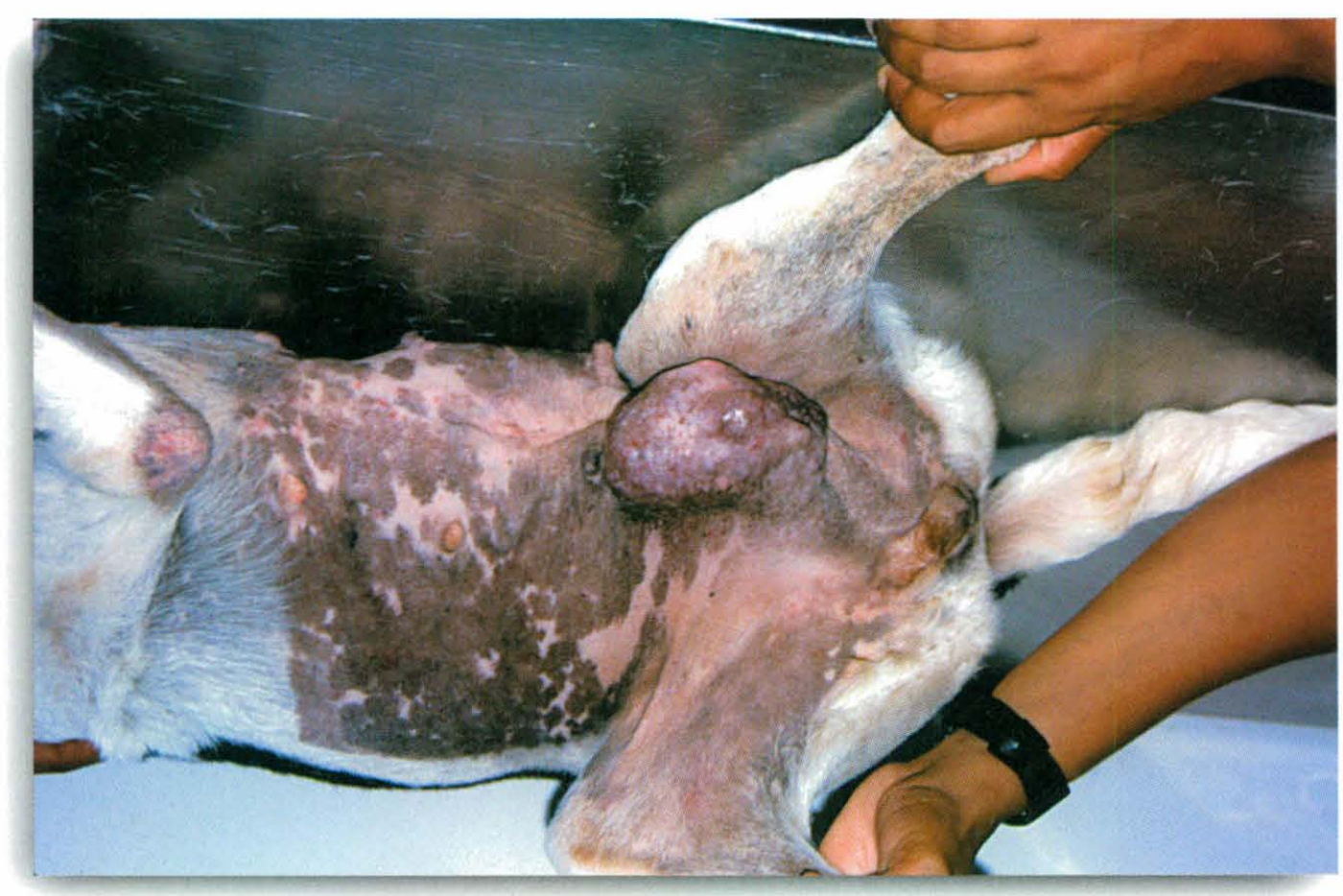

Figura 1. Aspecto geral de neoplasia mamária em cadela.

A maioria dos tumores mamários nos cães é classificada como maligno, e também quase a totalidade dos tumores mamários felinos (86\%) são malignos. O prognóstico para ambas, cadelas e gatas, com tumores malignos, é de reservado a mau (HARVEY, 1996; JOHNSTON, 1998).

Esses tumores são muito raros em machos, representando cerca de $1 \%$ de todas as neoplasias mamárias descritas. Assim como nos seres humanos, a maioria dos tumores em cães machos são neoplasias agressivas (LOAR, 1992).

O desenvolvimento da neoplasia na cadela depende, em grande parte, de hormônios. O risco de ocorrência de tumor mamário é de aproximadamente $0,5 \%$ para as cadelas castradas antes de seu primeiro estro, $8 \%$ para as cadelas castradas após o primeiro ciclo estral, e $26 \%$ para as castradas após dois ou mais ciclos estrais (WITHROW e O'BRIEN, 1997).

O'KEEFE (1997) estabelece que a avaliação diagnóstica de cães com tumores de mama deve constar de exame físico. Radiografias torácicas devem também ser avaliadas em busca de metástases pulmonares antes da exérese cirúrgica.

\section{Técnicas cirúrgicas indicadas}

O método primário para tratar os tumores de mama em cadelas e gatas é a mastectomia; porém, as taxas de cura ainda são baixas para pacientes com ma- mopatia maligna, pois é o comportamento do tumor, e não a extensão do tratamento, o que determina o destino final do paciente (HARVEY, 1996).

A quantidade de tecido mamário a ser removida durante a mastectomia em uma cadela ou em uma gata é influenciada por vários fatores, incluindo o tamanho, a consistência e a localização do tumor, e o porte, a idade e o estado fisiológico do paciente (HARVEY, 1996).

O'KEEFE (1997), McCAW (1996) e JOHNSTON (1998) citam e definem vários tipos de mastectomia:

- lumpectomia (nodulectomia) - remoção do tumor sem qualquer tecido mamário circundante. Utilizase a lumpectomia quando o tumor é pequeno, encapsulado e não invasivo;

- mastectomia parcial - remoção do tumor e de uma margem circundante de tecido mamário. É indicado para tumores pequenos ou moderados em tamanho (2 $\mathrm{cm}$ de diâmetro) e que ocupam somente uma porção de uma glândula mamária individual;

- mastectomia simples - remoção de toda a glândula mamária que contém o tumor;

- mastectomia regional (mastectomia radical modificada) - remoção de grupo(s) de glândulas mamárias, dependendo de qual(is) contenha(m) tumor(es);

- mastectomia unilateral completa (mastectomia radical) - remoção de todas as glândulas mamárias, tecidos interpostos e linfonodos regionais do mesmo antímero;

- mastectomia bilateral completa e simultânea (mastectomia radical bilateral) - remoção de ambas as cadeias mamárias inteiras, dos tecidos interpostos e dos linfonodos regionais.

Segundo WITHROW e O'BRIEN (1997), nas gatas, a mastectomia unilateral completa é o procedimento de eleição para todos os tumores mamários, pois a maioria desses tumores nos felinos é maligna.

A cirurgia permanece sendo a mais importante terapia para a maioria dos tumores mamários sólidos 
COELHO, M. C. O C.; COUTINHO, L. T.; ACETO, M. L.; MONTEIRO, V. L.; ARAÚJO, P. F. B.; BRITTO, K. M. Plastia em duplo "M" ou "V" para mastectomia / Double "M" or "V" plasty for mastectomy. / Rev. educ. contin. CRMV-SP / Continuous Education Journal CRMV-SP, São Paulo, volume 3, fascículo 3, p. 033 - 036, 2000.

(LOAR, 1992). O autor cita, ainda, a quimioterapia e a radioterapia como condutas terapêuticas, mas reforça que o procedimento cirúrgico é o tratamento de escolha para os tumores mamários sem característica de afecção metastática ou de carcinoma metastático.

O padrão de excisão cirúrgica é baseado na drenagem linfática e deve ser aceito o seguinte princípio: sempre que houver neoplasia, a glândula afetada deve ser removida com todas as glândulas existentes entre ela e o nódulo linfático receptor (HICKMAN e WALKER, 1983).

A técnica básica para a mastectomia segue a remoção de um segmento cutâneo, que engloba a(s) glândula(s) mamária(s) afetada(s), através de uma incisão elíptica ao redor da(s) glândula(s) a ser(em) removida(s) (BERGE,1978; HICKMAN e WALKER, 1983; McCAW, 1996).

O tipo histológico da neoplasia é o fator que influencia o prognóstico, assim como o diâmetro do tumor, o grau de invasibilidade, a diferenciação celular, o envolvimento dos linfonodos e a reatividade linfóide. Já a idade do paciente, o número de tumores presente, a localização do tumor, o tipo de cirurgia e ovário-histerectomia simultânea à mastectomia são fatores que aparentemente não alteram o prognóstico (O’KEEFE, 1997).

Dependendo da experiência, da habilidade do cirurgião e, muitas vezes, da localização e extensão da neoplasia, a incisão praticada em forma de elipse, circundando a neoplasia, deixa defeitos cutâneos ("orelhas", dobras ou rugas cutâneas) nas extremidades da incisão, ocasionando uma oclusão menos estética (SWAIM, 1998).

Segundo SWAIM (1998), a plastia em duplo "M", que pode ser considerada também como duplo "V", reduz o comprimento da excisão e a quantidade de tecido removido comparada à excisão fusiforme, permitindo, ainda, uma oclusão mais estética.

HENDERSON (1980) usou a plástica em "V" para reparar o defeito da pele deixado pela mastectomia bilateral de glândulas torácicas; tal defeito, após suturado, assume a forma de "Y". O mesmo autor afirma que tal técnica diminui a tensão da sutura e permite uma oclusão esteticamente melhor.

A plastia que emprega a técnica de duplo "M" ou "V" na mastectomia em cadelas, por ser considerada simples, pode ser utilizada como opção de tratamento cirúrgico.

$\mathrm{Na}$ avaliação desta técnica operatória observa-se que a incisão da pele é bastante prática pela facilidade de sua execução, haja visto que a região incisada é topograficamente plana. O tempo utilizado para realizar a incisão é superior ao de uma incisão elíptica, já que a incisão por completo consta de quatro pequenas incisões a mais.

A quantidade de tecido excisado é menor, uma vez que o tecido em forma de "V" é preservado pela técnica (JOHNSTON, 1998). Como preservar o tecido implica menor formação de espaço morto, conseqüentemente, diminui-se a formação de edemas e seromas, promovendo uma melhor cicatrização (HENDERSON, 1980).

A estética na oclusão da ferida pode ser considerada boa, haja visto a ausência de formação de defeitos cutâneos nas extremidades, conforme menciona HENDERSON (1980).

Conforme citam SWAIM (1998), HARVEY (1996) e HENDERSON (1980), quanto menor a tensão, melhor a cicatrização e esta técnica, que mantém o tecido em forma de "V", divide a tensão entre as bordas (principalmente a das extremidades), diminuindo-a no momento da dermorrafia, promovendo, conseqüentemente, melhor cicatrização.

Na oclusão da ferida operatória, observa-se a eliminação de defeitos de oclusão ("orelhas", dobras ou rugas cutâneas), principalmente nas extremidades, conforme relatou SWAIM (1998), podendo, desta forma, esta técnica ser praticada por cirurgiões menos experientes, sendo, consequentemente, uma vantagem na sua indicação.

\section{Conclusão}

A técnica de plastia em duplo "M" ou "V" é viável e pode ser empregada como alternativa na exérese de neoplasia mamária.

\section{SUMMARY}

The five mammary gland pairs of dogs are parallel and have a median distribution from the axillary to the inguinal region. Mammary neoplasia is the most common pathology of these glands and is the main cause for radical mastectomy. Double "M" or "V" plasty is described as an alternative technique to improve esthetics and the healing process.

Key words: plasty, mastectomy, neoplasia. 
COELHO, M. C. O C.; COUTINHO, L. T.; ACETO, M. L.; MONTEIRO, V. L.; ARAÚJO, P. F. B.; BRITTO, K. M. Plastia em duplo "M" ou "V" para mastectomia / Double " $M$ " or "V" plasty for mastectomy. / Rev. educ. contin. CRMV-SP / Continuous Education Journal CRMV-SP, São Paulo, volume 3, fascículo 3, p. $033-036,2000$.

\section{REFERÊNCIAS BIBLIOGRÁFICAS}

1 - BERGE, E., Técnica operatoria veterinária, 6. ed., Barcelona: Labor, 1978. Cap. 6, p. 375-7: Extirpación de tumores mamarios en la pera y la gata.

2 - ELLENPORT, C. R. Aparelho urogenital do carnívoro, In: SISSON, S.; GROSSMAN, J. D.; GETTY, R. Anatomia dos animais domésticos. 5. ed. Rio de Janeiro: Interamericana, 1986., cap.53, p. 1489-93.

2 - HARVEY, J. Glândulas mamárias. In: BOJRAB, M. J., Técnicas atuais em cirurgia de pequenos animais, 3. ed. São Paulo: Roca, 1996, cap. 35, p. 425-9.

3 - HENDERSON, R. A. Mammary tumors. In: SWAIM, S. F. Surgery of traumatized skin. Philadelphia: Lea \& Febiger, 1980. Cap. 2, p. 40-67.

4 - HICKMAN, J.; WALKER, R. G., Atlas de cirurgia veterinária. 2. ed. Rio de Janeiro: Guanabara Koogan, 1983. Cap. 5, p. 96-7:Glândulas mamárias e teto.

5 - JOHNSTON, D. S. Sistemas reprodutivos. In: SLATER, D. Manual de cirurgia de pequenos animais. 2. ed, São Paulo: Manole, 1998. v. 2 Cap,159, p. 2567-80.
6 - LOAR, A. S. Tumores do sistema genital e glândulas mamárias. In: ETTINGER, S. J., Tratado de medicina interna veterinária: moléstia do cão e do gato, 3. ed. São Paulo: Manole, 1992. v.4. cap. 102, p. 1894-905.

8 - McCAW, D. L. Moléstia da glândula mamária. In: BOJRAB, M. J., Mecanismo da moléstia na cirurgia dos pequenos animais, 2. ed, São Paulo; Manole, 1996, cap. 29, p. 216-9.

9 - O'KEEFE, D. A. Tumores do sistema genital masculino e feminino. In: ETTINGER, S. J.; FELDEMAN, E. C., Tratado de medicina interna veterinária: moléstia do cão e do gato, 4 . ed. São Paulo: Manole: 1997. v.2. cap. 131, p. 2344-50.

10 - SWAIM, S. F. Princípios da cirurgia plástica e reconstrutiva. In: SLATER, D. Manual de cirurgia de pequenos animais. 2. ed, São Paulo: Manole, 1998. v. 1, cap. 26, p. 34864.

11 - WITHROW, J. S; O'BRIEN, M.G. Oncologia cirúrgica. In: ETTINGER, S. J.; FELDEMAN, E. C., Tratado de medicina interna veterinária: moléstia do cão e do gato, 4 . ed. São Paulo: Manole, 1997. v.1. cap. 76, p. 723-31.

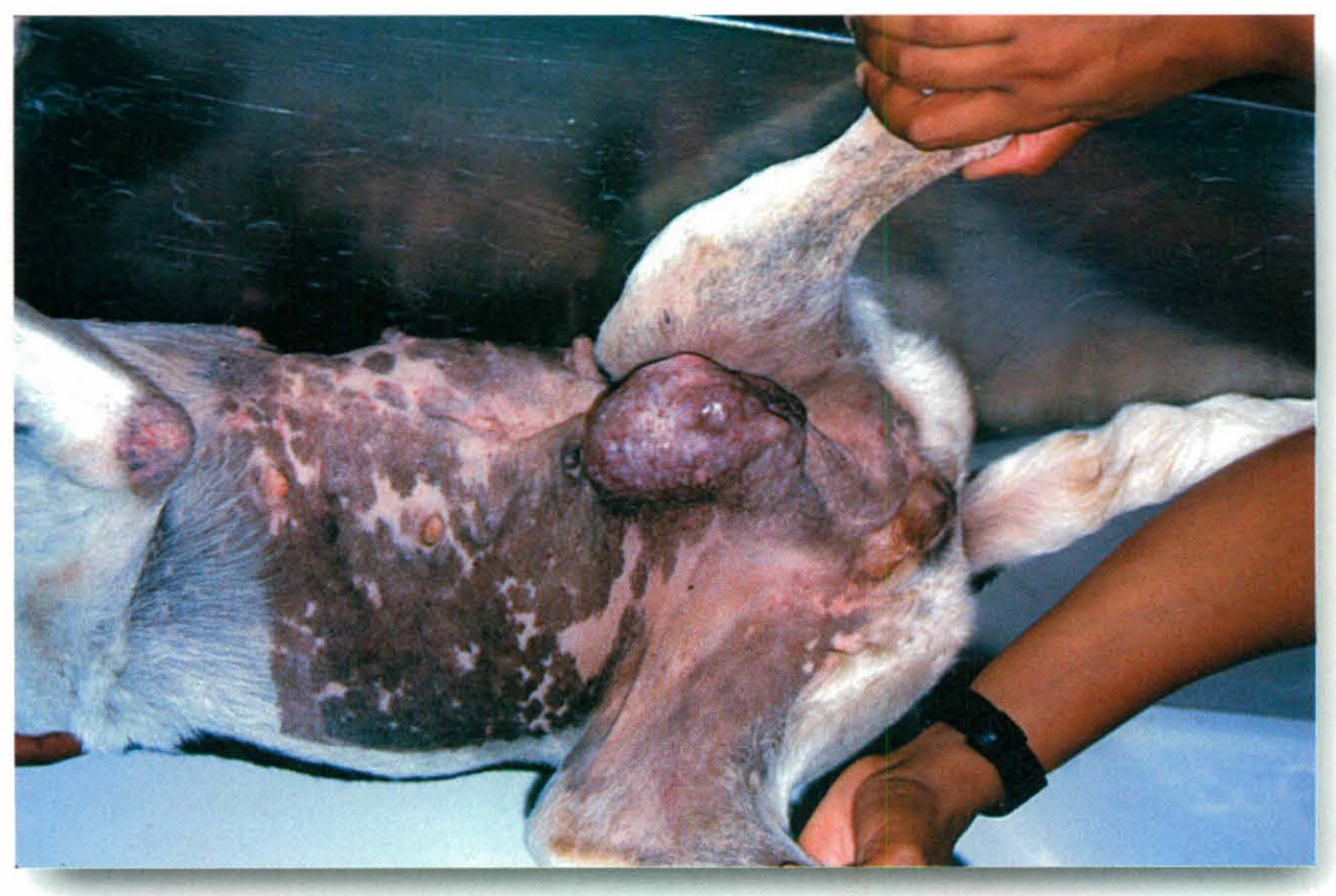

